\title{
A leap forward in the endovascular management of acute basilar artery occlusion since the appearance of stent retrievers: a single-center comparative study
}

\author{
Robert Fahed, MD, ${ }^{1}$ Federico Di Maria, MD, ${ }^{1}$ Charlotte Rosso, MD, PhD, ${ }^{2,3,4}$ Nader Sourour, MD, ${ }^{1}$ \\ Vincent Degos, MD, PhD, ${ }^{3,5}$ Sandrine Deltour, MD, ${ }^{2}$ Flore Baronnet-Chauvet, MD, PhD, ${ }^{2,3}$ \\ Anne Léger, MD, ${ }^{2}$ Sophie Crozier, MD, PhD, ${ }^{2}$ Joseph Gabrieli, MD, ${ }^{1,3}$ Yves Samson, MD, ${ }^{2,3,4}$ \\ Jacques Chiras, MD, ${ }^{1,3}$ and Frédéric Clarençon, MD, PhD ${ }^{1,3}$
}

\begin{abstract}
Departments of ${ }^{1}$ Interventional Neuroradiology, ${ }^{2}$ Vascular Neurology, and ${ }^{5}$ Anesthesiology, Pitié-Salpêtrière Hospital; ${ }^{3} \mathrm{Paris} \mathrm{VI}$ University, Pierre et Marie Curie; and ${ }^{4}$ Centre de Recherche de l'Institut du Cerveau et de la Moelle Épinière, INSERM, Paris, France
\end{abstract}

OBJECTIVE Contrary to acute ischemic stroke involving the anterior circulation, no randomized trial has yet demonstrated the safety and effectiveness of endovascular management in acute basilar artery occlusion (BAO). Recently developed thrombectomy devices, such as stentrievers and aspiration systems, have helped in improving the endovascular management of acute ischemic stroke. The authors sought to assess the impact of these devices in the endovascular treatment of acute BAO.

METHODS A retrospective analysis of 34 consecutive patients treated in Pitié-Salpêtrière Hospital for acute BAO was carried out. All patients had undergone an endovascular procedure. In addition to the global results in terms of safety and effectiveness (recanalization rate and 3-month clinical outcome based on the modified Rankin Scale [mRS]), the authors aimed to determine if the patients treated with the most recently developed devices (i.e., the Solitaire stentriever or the ADAPT catheter) had better angiographic and clinical outcomes than those treated with older endovascular strategies.

RESULTS The overall successful recanalization rate (thrombolysis in cerebral infarction score 2b-3) was $50 \%$ (17 of 34 patients). A good clinical outcome (mRS score 0-2 at 3-month follow-up) was achieved in 11 (32.3\%) of 34 patients. The mortality rate at 3 -month follow-up was $29.4 \%$ (10 of 34 patients). Patients treated with the Solitaire stentriever and the ADAPT catheter had a higher recanalization rate (12 [92.3\%] of 13 patients vs 5 [23.8\%] of 21 patients, $p=0.0002)$ and a shorter mean $( \pm \mathrm{SD}$ ) procedure duration ( $88 \pm 31$ minutes vs $126 \pm 58$ minutes, $p=0.04$ ) than patients treated with older devices.

CONCLUSIONS The latest devices have improved the effectiveness of mechanical thrombectomy in acute BAO. Their use in further studies may help demonstrate a benefit in the endovascular management of acute BAO.

https://thejns.org/doi/abs/10.3171/2016.2.JNS151983

KEY WORDS basilar artery occlusion; thrombectomy; endovascular; stent retriever; vascular disorders

$\mathrm{B}$ ASILAR artery occlusion (BAO) is a rare (1\%) but severe subtype of stroke, associated with a high spontaneous mortality rate $(80 \%-90 \%) .{ }^{16}$ When nonfatal, BAO may lead to severe neurological disability. The endovascular management of acute ischemic stroke has gained acceptance over the last decade, and several randomized controlled trials (RCTs) have recently shown its benefit. ${ }^{3,5,11,15,26}$ Nevertheless, none of these studies included patients with acute BAO.

Recently developed thrombectomy devices, such as the Solitaire stentriever (Covidien) and the ADAPT system (Penumbra), have contributed to the positive results of

ABBREVIATIONS BAO = basilar artery occlusion; $\mathrm{CTA}=\mathrm{CT}$ angiography; DSA = digital subtraction angiography; DWI = diffusion-weighted imaging; $\mathrm{DWI}-\mathrm{pc}-\mathrm{ASPECTS}=$ DWI-posterior circulation-Alberta stroke program early CT score; IQR = interquartile range; IV = intravenous; $\mathrm{mRS}=$ modified Rankin Scale; MT = mechanical thrombectomy; NIHSS = National Institutes of Health Stroke Scale; RCT = randomized controlled trial; $\mathrm{TICl}=$ thrombolysis in cerebral infarction; TOAST = Trial of Org 10172 in Acute Stroke Treatment; VA = vertebral artery.

SUBMITTED August 23, 2015. ACCEPTED February 22, 2016.

INCLUDE WHEN CITING Published online June 3, 2016; DOI: 10.3171/2016.2.JNS151983. 
recent trials for mechanical thrombectomy (MT), as they have dramatically improved the recanalization rate and the speed of endovascular procedures. ${ }^{12,31}$

We report the results of our single-center experience in endovascular mechanical treatment of ischemic stroke with $\mathrm{BAO}$, focusing on the comparison between the most recent thrombectomy devices and the old ones, in terms of safety, recanalization rate, and clinical outcome.

\section{Methods \\ Patient Population}

We retrospectively analyzed the charts of 34 consecutive patients $(24$ males, mean age $[ \pm \mathrm{SD}] 62.2 \pm 13.9$ years, range 29-88 years) who presented with $\mathrm{BAO}$ and underwent endovascular treatment between April 2006 and January 2015 in Pitié-Salpêtrière Hospital. All patients were referred to our stroke unit for the suspicion of an acute stroke. BAO was detected by 3D time-offlight MR angiography in 30 patients or CT angiography (CTA) in 4 patients and was confirmed on digital subtraction angiography (DSA) in all cases. This study was approved by the Pitié-Salpêtrière ethics committee; no patient informed consent was required because this was a retrospective analysis of anonymous patient records and imaging data.

\section{Clinical Assessment and Follow-Up}

For each patient, the National Institutes of Health Stroke Scale (NIHSS) score was independently assessed by a stroke neurologist on admission, at 24 hours, and 7 days after admission. Etiologies of the BAOs were systematically recorded and classified according to the criteria of the Trial of Org 10172 in Acute Stroke Treatment (TOAST). ${ }^{2}$ The modified Rankin Scale (mRS) scores were assessed at 3-month follow-up by a stroke neurologist.

\section{Preprocedure and Postprocedure Imaging Assessments}

Brain MRI including diffusion-weighted imaging (DWI) was performed preprocedure for $30(88.2 \%)$ of 34 patients. The remaining 4 patients (11.8\%) underwent CT with CTA on admission (in cases of contraindication for MRI or when MRI facility was not available). Brain MR images were retrospectively reviewed by 2 interventional neuroradiologists (R.F. and F.C.), with 3 and 8 years of experience in endovascular treatment, respectively. The DWI-posterior circulation-Alberta stroke program early CT score (DWI-pc-ASPECTS) ${ }^{29}$ was assessed in consensus for each patient.

All the patients underwent brain MRI or CT within 48 hours following the endovascular procedure, and they underwent later brain imaging if it was deemed necessary by the neurologist. The presence of a hemorrhagic transformation within 7 days after the procedure was systematically assessed according to the intravenous (IV) alteplase in acute ischemic stroke (ECASS II) study criteria. ${ }^{13} \mathrm{~A}$ hemorrhagic transformation was defined as symptomatic if associated with clinical deterioration (e.g., drowsiness, worsening of the hemiparesis, increase in the NIHSS score of 4 or more points).

\section{Endovascular Procedure}

All endovascular procedures were performed under general anesthesia via femoral access (6F femoral sheath). Both vertebral arteries (VAs) were successively catheterized by means of a $6 \mathrm{~F}$ guiding catheter (Envoy, Cordis Endovascular). In case of significant tortuosity, the VAs could be catheterized with a regular $5 \mathrm{~F}$ catheter. Finally, when navigation was very difficult, only the dominant VA was catheterized. DSA was performed in anteroposterior, lateral, and oblique projections. With a microcatheter navigated into the basilar artery, recanalization was then achieved through 1 or more of the following methods: endovascular techniques available from April 2006 to June 2010 involving clot fragmentation with a microguide wire (13 [38.2\%] of 34 patients), thromboaspiration with a syringe (10 [29.4\%] of 34 patients), MT with the Catch thrombectomy device (Balt Extrusion) (9 [26.5\%] of 34 patients), Hyperglide balloon angioplasty (Covidien) (2 [5.9\%] of 34 patients), intra-arterial infusion of abciximab (7 [20.6\%] of 34 patients), and/or alteplase (12 [35.3\%] of 34 patients). Additional techniques available since June 2010 include MT with the Solitaire stentriever (11 [32.3\%] of 34 patients) and thromboaspiration with the ADAPT system (4 [11.8\%] of 34 patients).

Since 2006, all patients with acute BAO and without contraindication received an IV bolus of $0.25 \mathrm{mg} / \mathrm{kg}$ abciximab within 12 hours of the onset of symptoms before the endovascular procedure. This protocol was established in our institution after the publication of promising results from a randomized study in $2005 .{ }^{1}$ In total, 23 (67.6\%) of 34 patients received IV abciximab and 2 (5.9\%) of 34 patients received IV alteplase. There have been no therapeutic modifications regarding the medical management of acute BAO between 2006 and 2015.

Time delays between the last significant clinical worsening and the femoral puncture were systematically collected. Procedure duration, defined as the delay between the femoral puncture and the recanalization or procedure discontinuation, was assessed as well. The recanalization of the basilar artery was graded according to the thrombolysis in cerebral infarction (TICI) score..$^{14} \mathrm{~A}$ successful recanalization was defined by a TICI score of $2 b-3$ at the end of the procedure.

Procedure-related complications were systematically noted.

\section{Statistical Analysis}

Baseline characteristics of patients with a favorable outcome (defined as mRS score 0-2 at 3-month followup) were compared with those with a poor outcome (defined as mRS score 3-6 at 3-month follow-up). We also compared patient characteristics and outcomes for patients treated with the latest endovascular devices (i.e., Solitaire and/or ADAPT system) and patients treated with older devices.

Data are presented as percentage (count) and mean $( \pm$ SD) for continuous variables or median (interquartile range [IQR]) for categorical variables. Comparisons between patients with a favorable outcome and a poor outcome were performed using $\chi^{2}$ tests for categorical variables and Student $t$-test for continuous variables (the 
Mann-Whitney U-test was used for the skewed distribution).

All statistical tests were performed using MedCalc software version 12.7.4 for Windows. A p value $<0.05$ was considered as statistically significant.

\section{Results}

Thirty-four patients (24 men [70.6\%], mean age 62.2 \pm 13.9 years) were treated in our center for ischemic stroke with BAO (Table 1). The median initial NIHSS score was 26.5 (IQR 12-35) (range 4-42). Four patients (11.8\%) had an atheromatous etiology (TOAST 1), 14 patients (41.1\%) had cardioembolism (TOAST 2), 2 patients (5.8\%) had a stroke secondary to another determined etiology (TOAST 4 [including 1 VA dissection]), and 14 patients (41.1\%) had an undetermined etiology (TOAST 5).

Twenty-three patients $(67.6 \%)$ received IV abciximab and 2 patients $(5.8 \%)$ received IV thrombolysis with alteplase before the endovascular procedure. The remaining 9 patients $(26.5 \%)$ either had a contraindication or were beyond the timeframe for IV treatment.

At 3-month follow-up, 11 patients $(32.4 \%)$ had a good clinical outcome and 23 patients $(67.6 \%)$ had a poor clini- cal outcome (10 [29.4\%] of 34 died). Patients with a good outcome had a lower NIHSS score at Day 1 and at Day 7 ( $\mathrm{p}=0.0001)$. Cardioembolic strokes (TOAST 2) were significantly more frequent in patients with a good clinical outcome than in patients with a poor clinical outcome (8 [72.7\%] of 11 vs 6 [26.1\%] of 23, p=0.02).

\section{Preprocedure Imaging Findings}

Prethrombectomy brain MRI was performed in 30 (88.2\%) of 34 patients. Among the patients who underwent MRI, the median DWI-pc-ASPECT score was 6 (IQR 5-8), with a statistically significant difference between good and poor outcome groups (Table 1) ( $p=0.0001)$. Additionally, there was a trend toward a statistically significant association between thalamic infarction (unilateral or bilateral) evident on initial brain MRI and a poor clinical outcome at 3-month follow-up (7 [33.3\%] of 21 vs 0 [0\%] of $9, \mathrm{p}=0.07)$.

\section{Endovascular Procedure and Use of the Latest Thrombectomy Devices}

There were no differences between patients with good clinical outcome and poor clinical outcome regarding the

TABLE 1. Patient demographics and clinical characteristics*

\begin{tabular}{|c|c|c|c|c|}
\hline Characteristic & Overall Population $(n=34)$ & Pts w/ GCO† $(n=11)$ & Pts w/ PCO $\ddagger(n=23)$ & p Value \\
\hline Male sex & $24(70.6)$ & $8(72.7)$ & $16(69.6)$ & NS \\
\hline Mean age in yrs \pm SD & $62.2 \pm 13.9$ & $61.0 \pm 12.9$ & $62.8 \pm 14.5$ & NS \\
\hline \multicolumn{5}{|l|}{ Median NIHSS (IQR) } \\
\hline Initial & $26.5(12.0-36.0)$ & $21.0(6.0-30.5)$ & $30.0(17.0-36.0)$ & NS \\
\hline Day 1 & $29.0(3.0-36.0)$ & $3.0(1.0-3.0)$ & $35.0(30.0-36.0)$ & 0.0001 \\
\hline Day 7 & $3.0(1.0-35.0)$ & $1.0(0-1.0)$ & $30.0(14.5-35.0)$ & $<0.0001$ \\
\hline \multicolumn{5}{|l|}{ TOAST criteria } \\
\hline 1 (atheroma) & $4(11.8)$ & $2(18.2)$ & $2(8.7)$ & NS \\
\hline 2 (cardioembolism) & $14(41.1)$ & $8(72.7)$ & $6(26.1)$ & 0.02 \\
\hline 4 (dissection/other) & $2(5.8)$ & $0(0)$ & $2(8.7)$ & NS \\
\hline 5 (undetermined etiology) & $14(41.1)$ & $1(9.1)$ & $13(56.6)$ & 0.01 \\
\hline \multicolumn{5}{|l|}{ Antithrombotic treatment } \\
\hline Abciximab & $23(67.6)$ & $8(72.7)$ & $15(65.2)$ & NS \\
\hline Alteplase & $2(5.8)$ & $1(9.1)$ & $1(4.3)$ & NS \\
\hline Median DWI-pc-ASPECTS (IQR) & $6(5-8)^{* *}$ & $8(8-8) \dagger \dagger$ & $6(5-6) \ddagger \ddagger$ & 0.0001 \\
\hline $\begin{array}{l}\text { Mean delay from LSCW to arrival in angiography suite } \\
\text { in mins } \pm \text { SD }\end{array}$ & $375.1 \pm 221.4$ & $290.3 \pm 103.6$ & $412.0 \pm 249.4$ & NS \\
\hline Mean duration of procedure in minutes \pm SD & $112.0 \pm 52.0$ & $105.0 \pm 56.0$ & $115.0 \pm 52.0$ & NS \\
\hline Successful recanalizationף & $17(50.0)$ & $8(72.7)$ & $9(39.1)$ & NS \\
\hline Major complications & $2(5.9)$ & $0(0)$ & $2(8.7)$ & NS \\
\hline Hemorrhagic transformations at $<7$ days & $3(8.8)$ & $0(0)$ & $3(13.0)$ & NS \\
\hline 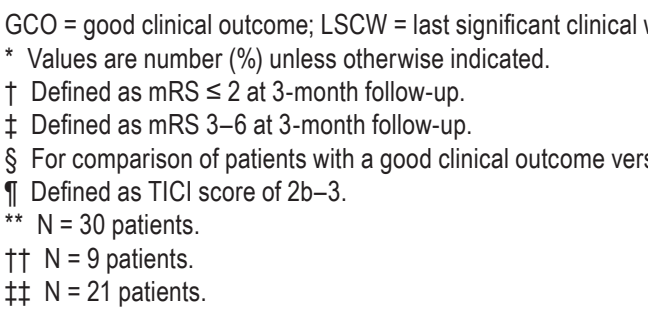 & s patients with a poor clinical out & $=$ poor clinical outcome; $p$ & patients. & \\
\hline
\end{tabular}


delay between last clinical worsening and femoral puncture, procedure duration, and successful recanalization rate (Table 1).

Overall, $13(38.2 \%)$ of 34 patients were treated with the Solitaire and/or ADAPT system, and 21 (61.8\%) of 34 patients were treated with other older devices. Despite similar initial characteristics (age, initial NIHSS score, and DWI-pc-ASPECTS on initial brain MRI), the patients treated with the Solitaire and/or ADAPT system underwent a significantly faster endovascular procedure $(88 \pm$ 31 minutes vs $126 \pm 58$ minutes $[\mathrm{p}=0.04]$ ) and showed a significantly higher successful recanalization rate (TICI $2 \mathrm{~b}-3$ in 12 [92.3\%] of 13 patients vs 5 [23.8\%] of 21 patients, $\mathrm{p}=0.0002)$ than patients treated with older devices.

At 3-month follow-up, 7 (53.8\%) of 13 patients treated with the Solitaire and/or ADAPT system versus $4(19.0 \%)$ of 21 patients who were treated with other devices had an mRS score of $0-2(p=0.06)$. Also, $4(30.8 \%)$ of 13 patients treated with the Solitaire and/or ADAPT system versus $6(28.6 \%)$ of 21 patients treated with other devices were deceased $(\mathrm{p}=1)$.

In 5 cases (14.7\%), the occluded segment was impossible to reach due to significant vessel tortuosity; as a consequence, we were only able to inject intra-arterial alteplase. All of these patients had a poor clinical outcome at 3-month follow-up.

Two patients (5.9\%) suffered from complications during the endovascular procedure: 1 patient with vessel perforation and 1 with distal thromboembolism. Both adverse events led to a poor clinical outcome and occurred with devices other that the Solitaire and/or ADAPT system (2 [9.5\%] of 21 patients); however, this was not statistically significantly different from the adverse events rate in the group treated with the Solitaire and/or ADAPT system (0 [0\%] of 13 patients, $\mathrm{p}=0.51$ ).

\section{Findings on Postprocedure Imaging}

Four symptomatic hemorrhagic transformations were observed within 7 days of the procedure, and all of them occurred in patients with a poor clinical outcome, including 3 deceased patients.

\section{Discussion}

Mechanical thrombectomy in conjunction with IV thrombolysis is now considered the treatment of choice for acute ischemic stroke with large-vessel occlusion in the anterior circulation. Although acute ischemic strokes secondary to BAO carry a poorer prognosis and a higher mortality rate than those occurring in the anterior circulation, the benefit of endovascular thrombectomy in BAO remains to be proven by an RCT.

Our results seem to confirm previously published noncontrolled, nonrandomized data regarding the safety and effectiveness of this technique, especially with the use of the latest devices such as stentrievers and thromboaspiration catheters.

\section{Endovascular Procedure and Angiographic Results}

Over the last decades, MT devices have constantly evolved and their use has yielded a recanalization rate of over $80 \% .{ }^{12}$ Stentrievers have greatly improved the endovascular results in MT for acute ischemic stroke, ${ }^{8,32}$ and are partly responsible for the positive results of MT in the recent randomized trials. ${ }^{3,5,11,15,26}$ In 2013, 3 randomized trials evaluating the effectiveness of endovascular treatment in acute ischemic stroke of the anterior circulation had proven inconclusive, ${ }^{4,718}$ but only a minority of the patients included in these studies were treated with newgeneration devices such as stentrievers. In 2012, Saver et al. published the results of the SWIFT (Solitaire With the Intention For Thrombectomy) trial, a randomized study comparing the Solitaire stentriever with the MERCI device (Stryker Neurovascular), and concluded that patients treated with the Solitaire had a significantly higher recanalization rate, a better clinical outcome, and a lower mortality rate. ${ }^{27}$ Nevertheless, the vast majority of the patients enrolled in this study had presented with an anterior circulation ischemic stroke.

In our series, the group of patients who were treated with the most recent thrombectomy devices benefited by having a higher recanalization rate $(92.3 \%$ vs $23.8 \%$, $\mathrm{p}=$ $0.0002)$ and a shorter procedure duration $(88 \pm 31$ minutes vs $126 \pm 58$ minutes, $\mathrm{p}=0.04)$ compared with patients treated by older techniques (Table 2). Complication rates were similar in the 2 groups $(\mathrm{p}=0.51)$.

In a recent meta-analysis of patients treated for acute BAO with stentrievers, Gory et al. ${ }^{10}$ found a successful recanalization rate of $81 \%$ (95\% CI 73\%-87\%), a good clini-

TABLE 2. Comparison of patients treated with and without the most recent thrombectomy devices

\begin{tabular}{|c|c|c|c|}
\hline Characteristic & 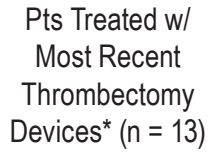 & $\begin{array}{l}\text { Pts Treated } \\
\text { w/ Older } \\
\text { Techniques } † \\
(n=21)\end{array}$ & $\begin{array}{c}p \\
\text { Valuef }\end{array}$ \\
\hline Mean age in yrs $\pm S D$ & $67.1 \pm 15.3$ & $59.2 \pm 12.3$ & NS \\
\hline Median Initial NIHSS (IQR) & $34(12-36)$ & $25(12-32)$ & NS \\
\hline $\begin{array}{l}\text { Median initial DWI-pc- } \\
\text { ASPECTS (IQR) }\end{array}$ & $8(6-8)^{\star *}$ & $6(5-8) \dagger \dagger$ & NS \\
\hline $\begin{array}{l}\text { Mean delay from LSCW } \\
\text { to arrival in angiograpy } \\
\text { suite in mins } \pm \text { SD }\end{array}$ & $404.3 \pm 223.3$ & $358.4 \pm 224$ & NS \\
\hline $\begin{array}{l}\text { Successful recanaliza- } \\
\text { tion, } \S n(\%)\end{array}$ & $12(92.3)$ & $5(23.8)$ & 0.0002 \\
\hline $\begin{array}{l}\text { Mean procedure duration } \\
\text { in mins } \pm S D\end{array}$ & $88 \pm 31$ & $126 \pm 58$ & 0.04 \\
\hline GCO,,$n(\%)$ & $7(53.8)$ & $4(19.0)$ & 0.06 \\
\hline $\begin{array}{l}\text { Mortality at 3-mo follow- } \\
\text { up, n (\%) }\end{array}$ & $4(30.8)$ & $6(28.6)$ & NS \\
\hline \multicolumn{4}{|c|}{$\begin{array}{l}\text { * Solitaire and/or ADAPT devices. } \\
\dagger \text { CATCH device, fragmentation with microguide, intra-arterial infusion of } \\
\text { abciximab, intra-arterial infusion of alteplase. } \\
\text { † The } p \text { value compares patients with a good clinical outcome with patients } \\
\text { with a poor clinical outcome. } \\
\text { § Defined as TICl score of } 2 \text { b- } 3 \text {. } \\
\text { Tा Defined as mRS mRS } \leq 2 \text { at } 3 \text {-month follow-up. } \\
\text { ** } N=9 \text { patients. } \\
\dagger \dagger N=21 \text { patients. }\end{array}$} \\
\hline
\end{tabular}


cal outcome rate (mRS score $\leq 2)$ at 3-month follow-up in $42 \%(95 \%$ CI $36 \%-48 \%)$ of patients, and a mortality rate (mRS score 6 ) of $30 \%$ (95\% CI 25\%-36\%).

\section{Clinical Outcome}

The positive results of recent $\mathrm{RCTs} \mathrm{s}^{3,5,11,15,26}$ for anterior circulation strokes raise the critical question of whether mechanical thrombectomy (especially with these new devices) should be used as a first-line treatment of acute $\mathrm{BAO}$, without the need for a dedicated RCT. ${ }^{9}$ Our retrospective comparative series with a historical control cohort shows the technical benefits of the new endovascular devices regarding the procedure speed and the recanalization rate. Additionally, the use of the latest devices in the endovascular management of acute BAO may lead to a better clinical outcome at 3-month follow-up when compared with older devices (7 [53.8\%] of 13 patients vs 4 [19.0\%] of $21, \mathrm{p}=0.06$ ). This result was not statistically significant, which may be explained by our relatively small population or by a possibly inadequate patient selection that may have led to futile revascularizations (i.e., MT in patients with a large ischemic burden on the initial MRI). Systematic reviews of the literature focused on endovascular treatment results in $\mathrm{BAO}$ with ${ }^{10}$ and without ${ }^{19}$ new devices such as stent retrievers also seem to show higher rates of successful recanalization and good clinical outcome with last-generation devices (Table 3). ${ }^{10,19,23-25,33}$

Cardioembolic stroke etiology was statistically associated with a good clinical outcome $(p=0.02)$. Several factors may explain this correlation. First, in contrast to patients with severe atheroma (TOAST 1), patients with cardioembolism (TOAST 2) rarely have tortuous vessels and ostial stenosis or occlusion of the vertebral arteries, which makes the endovascular procedure less challenging.
In case of difficult catheterization, if the interventionist cannot reach the thrombus with the microcatheter, none of the recent devices can be used (stentrievers, thromboaspiration device), and the sole alternative is the intra-arterial infusion of thrombolytic agents. In our series, such a situation was faced in 5 (14.7\%) of 34 patients, and all of them had a poor clinical outcome. Moreover, cardioembolic strokes are usually not associated with an underlying basilar artery stenosis or an ulcerated plaque, which both tend to re-occlude very often after MT. Moreover, distal BAOs have been found to have a better prognosis in a recent study. ${ }^{10}$

In our study, there was a very strong correlation between low NIHSS scores on Day 1 and Day 7 and a good clinical outcome at 3-month follow-up (Table 1), despite a nonsignificant difference between the 2 groups (good and poor clinical outcome) regarding the initial NIHSS score at admission. Interestingly, contrary to recent studies, ${ }^{10,16}$ a younger age was not associated with a better prognosis in our series.

Most of our patients (30 [88.2\%] of 34) underwent brain MRI before the procedure, which allowed us to have a precise assessment of the ischemic lesion burden. We found that DWI-pc-ASPECTS was a very strong predictor of a good clinical outcome. MRI is a useful tool for pre-MT evaluation in patients with BAO. Indeed, most patients with BAO are in a comatose state (11 [32.3\%] of 34 patients in our series), which makes the initial neurological examination difficult. MRI helps to assess the lesion burden and provides criteria for the triage of patients with BAO, avoiding futile MT in patients with large lesions. Several scores have been built based on DWI lesion burden evaluation; $6,17,21,23$ they appear to be reliable tools for clinical outcome prediction in BAO.$^{22}$ Even if CT and

TABLE 3. Literature review results about treatments of acute stroke with BAO*

\begin{tabular}{|c|c|c|c|c|}
\hline Authors \& Year & No. of Pts & Successful Recanalization† & Good Clinical Outcomeł & Mortality Rate§ \\
\hline \multicolumn{5}{|c|}{ Medical treatment (IV thrombolysis) } \\
\hline Sairanen et al., 2011 & 116 & & $30(25.9)$ & $48(41.4)$ \\
\hline Lindsberg \& Mattle, 2006 & 76 & & $17(22.3)$ & $38(50.0)$ \\
\hline \multicolumn{5}{|c|}{ Endovascular treatment (IA thrombolysis) } \\
\hline Lindsberg \& Mattle, 2006 & 344 & $225(65.4)$ & $84(24.4)$ & $190(55.2)$ \\
\hline Renard et al., 2008 & 16 & $11(68.8)$ & $5(31.3)$ & $8(50.0)$ \\
\hline \multicolumn{5}{|c|}{$\begin{array}{l}\text { Mechanical thrombectomy (stentrievers/ } \\
\text { thromboaspiration) }\end{array}$} \\
\hline Roth et al., 2010 & 8 & $8(100.0)$ & $4(50.0)$ & $3(37.5)$ \\
\hline Gory et al., 2015 & 312 & $253(81.1)$ & $121(42.0)^{\star *}$ & $94(30.1)$ \\
\hline Gory et al., 2015 & 22 & $16(72.7)$ & $6(27.3)$ & $10(45.5)$ \\
\hline Yoon et al., 2015 & 50 & $48(96.0)$ & $27(54.0)$ & $6(12.0)$ \\
\hline Present study & 13 & $12(92.3)$ & $7(53.8)$ & $4(30.8)$ \\
\hline \multicolumn{5}{|c|}{$\begin{array}{l}\text { IA = intra-arterial. } \\
\text { * Values are number of patients }(\%) \text { unless otherwise indicated. } \\
\dagger \text { Defined as } \mathrm{TICl} \text { score of } 2 \mathrm{~b}-3 \text {. } \\
\text { † Defined as } \mathrm{mRS} \leq 2 \text { at } 3 \text {-month follow-up. } \\
\S \text { Mortality rate defined as mRS } 6 \text { at } 3 \text {-month follow-up. } \\
\text { † Systematic review. } \\
{ }_{* *} \text { Out of a total of } 288 \text { patients. }\end{array}$} \\
\hline
\end{tabular}


CTA, especially multiphase CTA, ${ }^{20}$ have been reported as reliable tools for the triage of patients with acute ischemic stroke involving the anterior circulation, it appears that, owing to CT posterior fossa artifacts, this imaging modality is far less valuable than MRI for the assessment of ischemic lesion burden in BAO. Additionally, MRI may help to estimate the delay between stroke onset and admission using the DWI-FLAIR mismatch. This evaluation may play a key role when the onset of symptoms cannot be determined. ${ }^{30}$

Surprisingly, we found no statistically significant difference between the 2 groups (good and poor clinical outcome) regarding the delay between last significant clinical worsening and the arrival in the angiography suite. Nevertheless, the delay between symptoms onset and recanalization remains a critical prognosis factor in several studies involving BAO.$^{28}$ Additionally, it should be mentioned that none of the patients treated over 8 hours after the last significant clinical worsening in our study had a good clinical outcome (6 [17.6\%] of 34 patients).

\section{Study Limitations}

This study has several limitations. First, this is a singlecenter retrospective study. Second, the use of IV abciximab before the endovascular procedure in the majority of the cases may have influenced the results in terms of angiographic recanalization. However, it should be mentioned that no recanalization was observed on initial DSA; this fact underlines the limited impact of abciximab on basilar artery recanalization. Additionally, the design of our study (retrospective historical cohort) may introduce a bias in our results since the patients' medical management may have improved in parallel with the development of thrombectomy devices. Nevertheless, such advances in medical management may only account for a better clinical outcome but not a higher recanalization rate. Finally, only 2 recently developed devices were used in our study. Many stentrievers are now available on the market. Even if the recanalization rates obtained with these different devices are within the same ranges, one may argue that our results cannot be reached with other recent MT devices.

\section{Conclusions}

Our series suggests that patients treated with the most recent MT devices for BAO may have a higher recanalization rate and undergo faster procedures than those treated with older endovascular techniques. There is a strong trend for patients treated with the most recent MT devices to have a better clinical outcome at 3-month follow-up.

\section{References}

1. Abciximab Emergent Stroke Treatment Trial (AbESTT) Investigators: Emergency administration of abciximab for treatment of patients with acute ischemic stroke: results of a randomized phase 2 trial. Stroke 36:880-890, 2005

2. Adams HP Jr, Bendixen BH, Kappelle LJ, Biller J, Love $\mathrm{BB}$, Gordon DL, et al: Classification of subtype of acute ischemic stroke. Definitions for use in a multicenter clinical trial. TOAST. Trial of Org 10172 in Acute Stroke Treatment. Stroke 24:35-41, 1993

3. Berkhemer OA, Fransen PS, Beumer D, van den Berg LA,
Lingsma HF, Yoo AJ, et al: A randomized trial of intraarterial treatment for acute ischemic stroke. N Engl J Med 372:11-20, 2015

4. Broderick JP, Palesch YY, Demchuk AM, Yeatts SD, Khatri $\mathrm{P}$, Hill MD, et al: Endovascular therapy after intravenous t-PA versus t-PA alone for stroke. N Engl J Med 368:893903, 2013

5. Campbell BC, Mitchell PJ, Kleinig TJ, Dewey HM, Churilov L, Yassi N, et al: Endovascular therapy for ischemic stroke with perfusion-imaging selection. N Engl J Med 372:1009_ 1018,2015

6. Cho TH, Nighoghossian N, Tahon F, Némoz C, Hermier M, Salkine F, et al: Brain stem diffusion-weighted imaging lesion score: a potential marker of outcome in acute basilar artery occlusion. AJNR Am J Neuroradiol 30:194-198, 2009

7. Ciccone A, Valvassori L: Endovascular treatment for acute ischemic stroke. N Engl J Med 368:2433-2434, 2013

8. Deshaies EM, Singla A, Villwock MR, Padalino DJ, Sharma $\mathrm{S}$, Swarnkar A: Early experience with stent retrievers and comparison with previous-generation mechanical thrombectomy devices for acute ischemic stroke. J Neurosurg 121:12-17, 2014

9. Fiorella D, Mocco J, Athur A, Siddiqui A, Heck D, Albuquerque F, et al: Randomized controlled trials for everything? J Neurointerv Surg 7:861-863, 2015

10. Gory B, Eldesouky I, Sivan-Hoffmann R, Rabilloud M, Ong E, Riva R, et al: Outcomes of stent retriever thrombectomy in basilar artery occlusion: an observational study and systematic review. J Neurol Neurosurg Psychiatry 87:520-525, 2016

11. Goyal M, Demchuk AM, Menon BK, Eesa M, Rempel JL, Thornton J, et al: Randomized assessment of rapid endovascular treatment of ischemic stroke. N Engl J Med 372:10191030,2015

12. Grech R, Mizzi A, Pullicino R, Thornton J, Downer J: Functional outcomes and recanalization rates of stent retrievers in acute ischaemic stroke: A systematic review and metaanalysis. Neuroradiol J 28:152-171, 2015

13. Hacke W, Kaste M, Fieschi C, von Kummer R, Davalos A, Meier D, et al: Randomised double-blind placebo-controlled trial of thrombolytic therapy with intravenous alteplase in acute ischaemic stroke (ECASS II). Lancet 352:1245-1251, 1998

14. Higashida RT, Furlan AJ, Roberts H, Tomsick T, Connors B, Barr J, et al: Trial design and reporting standards for intra-arterial cerebral thrombolysis for acute ischemic stroke. Stroke 34:e109-e137, 2003

15. Jovin TG, Chamorro A, Cobo E, de Miquel MA, Molina CA, Rovira A, et al: Thrombectomy within 8 hours after symptom onset in ischemic stroke. N Engl J Med 372:2296-2306, 2015

16. Jung S, Mono ML, Fischer U, Galimanis A, Findling O, De Marchis GM, et al: Three-month and long-term outcomes and their predictors in acute basilar artery occlusion treated with intra-arterial thrombolysis. Stroke 42:1946-1951, 2011

17. Karameshev A, Arnold M, Schroth G, Kappeler L, Stein P, Gralla J, et al: Diffusion-weighted MRI helps predict outcome in basilar artery occlusion patients treated with intraarterial thrombolysis. Cerebrovasc Dis 32:393-400, 2011

18. Kidwell CS, Jahan R, Gornbein J, Alger JR, Nenov V, Ajani $\mathrm{Z}$, et al: A trial of imaging selection and endovascular treatment for ischemic stroke. N Engl J Med 368:914-923, 2013

19. Lindsberg PJ, Mattle HP: Therapy of basilar artery occlusion: a systematic analysis comparing intra-arterial and intravenous thrombolysis. Stroke 37:922-928, 2006

20. Menon BK, d'Esterre CD, Qazi EM, Almekhlafi M, Hahn L, Demchuk AM, et al: Multiphase CT angiography: a new tool for the imaging triage of patients with acute ischemic stroke. Radiology 275:510-520, 2015 
21. Mourand I, Machi P, Nogué E, Arquizan C, Costalat V, Picot $\mathrm{MC}$, et al: Diffusion-weighted imaging score of the brain stem: A predictor of outcome in acute basilar artery occlusion treated with the Solitaire FR device. AJNR Am J Neuroradiol 35:1117-1123, 2014

22. Ostrem JL, Saver JL, Alger JR, Starkman S, Leary MC, Duckwiler G, et al: Acute basilar artery occlusion: diffusionperfusion MRI characterization of tissue salvage in patients receiving intra-arterial stroke therapies. Stroke 35: $30-$ e34, 2004

23. Renard D, Landragin N, Robinson A, Brunel H, Bonafe A, Heroum C, et al: MRI-based score for acute basilar artery thrombosis. Cerebrovasc Dis 25:511-516, 2008

24. Roth C, Papanagiotou P, Behnke S, Walter S, Haass A, Becker C, et al: Stent-assisted mechanical recanalization for treatment of acute intracerebral artery occlusions. Stroke 41:2559-2567, 2010

25. Sairanen T, Strbian D, Soinne L, Silvennoinen H, Salonen $\mathrm{O}$, Artto V, et al: Intravenous thrombolysis of basilar artery occlusion: predictors of recanalization and outcome. Stroke 42:2175-2179, 2011

26. Saver JL, Goyal M, Bonafe A, Diener HC, Levy EI, Pereira VM, et al: Stent-retriever thrombectomy after intravenous t-PA vs. t-PA alone in stroke. N Engl J Med 372:2285-2295, 2015

27. Saver JL, Jahan R, Levy EI, Jovin TG, Baxter B, Nogueira $\mathrm{RG}$, et al: Solitaire flow restoration device versus the Merci Retriever in patients with acute ischaemic stroke (SWIFT): a randomised, parallel-group, non-inferiority trial. Lancet 380:1241-1249, 2012

28. Singer OC, Berkefeld J, Nolte CH, Bohner G, Haring HP, Trenkler J, et al: Mechanical recanalization in basilar artery occlusion: the ENDOSTROKE study. Ann Neurol 77:415424,2015

29. Tei H, Uchiyama S, Usui T, Ohara K: Posterior circulation ASPECTS on diffusion-weighted MRI can be a powerful marker for predicting functional outcome. J Neurol 257:767773,2010

30. Thomalla G, Fiebach JB, Østergaard L, Pedraza S, Thijs V, Nighoghossian N, et al: A multicenter, randomized, double- blind, placebo-controlled trial to test efficacy and safety of magnetic resonance imaging-based thrombolysis in wake-up stroke (WAKE-UP). Int J Stroke 9:829-836, 2014

31. Turk AS, Frei D, Fiorella D, Mocco J, Baxter B, Siddiqui A, et al: ADAPT FAST study: a direct aspiration first pass technique for acute stroke thrombectomy. J Neurointerv Surg 6:260-264, 2014

32. Turk AS, Turner R, Spiotta A, Vargas J, Holmstedt C, Ozark $\mathrm{S}$, et al: Comparison of endovascular treatment approaches for acute ischemic stroke: cost effectiveness, technical success, and clinical outcomes. J Neurointerv Surg 7:666-670, 2015

33. Yoon W, Kim SK, Heo TW, Baek BH, Lee YY, Kang HK: Predictors of good outcome after stent-retriever thrombectomy in acute basilar artery occlusion. Stroke 46:2972-2975, 2015

\section{Disclosures}

The authors report no conflict of interest concerning the materials or methods used in this study or the findings specified in this paper.

\section{Author Contributions}

Conception and design: Fahed, Clarençon. Acquisition of data: Fahed, Di Maria, Rosso, Sourour, Deltour, Baronnet-Chauvet, Léger, Crozier, Gabrieli, Clarençon. Analysis and interpretation of data: Fahed, Di Maria, Sourour, Clarençon. Drafting the article: Fahed, Di Maria, Sourour. Critically revising the article: all authors. Reviewed submitted version of manuscript: Fahed, Rosso, Sourour, Degos, Deltour, Baronnet-Chauvet, Léger, Crozier, Gabrieli, Samson, Chiras. Statistical analysis: Fahed. Administrative/technical/material support: Fahed.

\section{Correspondence}

Frédéric Clarençon, Department of Interventional Neuroradiology, Pitié-Salpêtrière Hospital, 47-83 Boulevard de l'Hôpital, Paris 75013, France. email: fredclare5@msn.com. 